\title{
Interacción entre un fragmento peptídico del receptor tipo 1 de angiotensina humano y sistemas miméticos de membrana biológica
}

\section{Interaction between a peptide fragment of the human receptor type 1 of angiotensin and model membranes}

\author{
Nélida Marín Huachaca ${ }^{1}$, Clóvis R. Nakaie ${ }^{2}$ y Shirley Schreier ${ }^{1}$ \\ ${ }^{1}$ Departamento de Bioquímica de la Universidade de São Paulo, Av. Prof. Lineu Prestes 748, CEP: 05513-970 \\ São Paulo, Brasil \\ 2Departmento de Biofísica de la Universidade Federal de São Paulo, Rua 3 de Maio 100, CEP: 04044-020, \\ São Brasil.
}

DOI: https://doi.org/10.33017/RevECIPeru2016.0003/

\section{Resumen}

El receptor tipo 1 de angiotensina $\left(\mathrm{AT}_{1}\right)$ humano pertenece a la superfamilia de receptores acoplados a Proteínas G (GPCR). Estudios conformacionales de fragmentos peptídicos de GPCR requiere el uso de sistemas que mimeticen el ambiente del receptor. El presente estudio propone investigar la interacción del fragmento peptídico Ac-YRWPFGNYL-CONH 2 (fEC1), que corresponde a los residuos de aminoácidos 92 100 del primer bucle extracelular del receptor $\mathrm{AT}_{1}$ humano, con sistemas miméticos de membrana biológica micelas y vesículas unilamelares grandes (LUV). Las micelas fueron preparadas a partir de los lisofosfolípidos: 1-palmitoil-2-hidroxi-fosfatidilcolina (LPC) y 1-palmitoil-2-hidroxi-fosfatidilglicerol (LPG), mientras que, las LUV fueron preparadas a partir de 1-palmitoil-2-oleoil-fosfatidilcolina (POPC) y 1-palmitoil-2oleoil-fosfatidilglicerol (POPG). El péptido fEC1 fue sintetizado por el método de síntesis en fase sólida. Se realizaron medidas de fluorescencia utilizando, como sonda fluorescente intrínseca, el residuo de triptófano $\left(\mathrm{W}^{94}\right)$, presente en la secuencia de aminoácidos de fEC1. La longitud de onda de excitación ( $\lambda_{\text {exc }}$ ) fue de 195 $\mathrm{nm}$. Los espectros de fluorescencia de fEC1 $(10 \mu \mathrm{M})$ fueron obtenidos en concentraciones crecientes de lisofosfolípidos o de fosfolípidos. La intensidad de fluorescencia del péptido aumentó en la presencia de micelas tanto zwitteriónica (LPC) como aniónica (LPC: LPG, mol:mol) y, en la presencia de LUV aniónica (POPC:POPG, mol:mol). Asimismo, se observaron desplazamientos de las longitudes de onda de emisión máxima $\left(\lambda_{\max }\right)$ hacia el azul. Las alteraciones espectrales observadas son debido a la sensibilidad del triptófano a la polaridad del medio en que se encuentra. A partir de las isotermas de interacción fueron determinadas las constantes de asociación $\left(\mathrm{K}_{\mathrm{a}}\right)$. De acuerdo a estos valores, la interacción del péptido con los sistemas aniónicos fue mayor que con los zwitteriónicos debido a la contribución de fuerzas electrostáticas. Para los estudios de supresión de fluorescencia se utilizó acrilamida como supresor colisional y se determinaron las constantes de Stern-Volmer. Conforme a estos valores, el fluoróforo está más expuesto a la acrilamida cuando fEC1 está en solución que cuando está en la presencia de sistemas biomiméticos, lo cual es debido a la interacción del péptido con estos sistemas. Asimismo, se calcularon los valores de anisotropía de fluorescencia $(r)$ los cuales están relacionados al movimiento de difusión rotacional de un fluoróforo. De acuerdo a estos datos, el péptido presenta mayor movimiento de difusión rotacional en medio acuoso que cuando interactúa con los sistemas modelo. Los resultados obtenidos, a través de la fluorescencia de estado estacionario, muestran la interacción del fragmento peptídico fEC1 con micelas de lisofosfolípido, LUV de POPC: POPG y, en menor extensión, con LUV de POPC.

Descriptores: Receptor $A T_{1}$ humano, dicroísmo circular, fluorescencia, sistema mimético de membrana biológica 


\section{Abstract}

The type 1 angiotensin ( $A T_{1}$ ) receptor belongs to $G$ protein coupled receptors (GPCR) superfamily. Conformational studies of GPCR peptide fragments require the use of systems that mimic the receptor environment. The current study aims to investigate the interaction of the peptide fragment Ac-YRWPFGNYLCONH2 (fEC1), corresponding to amino acid residues $92-100$ of the first extracellular loop of the human AT 1 receptor, with model membranes -micelles and large unilamellar vesicles (LUV). The micelles were prepared from lysophospholipids: 1-palmitoyl-2-hydroxy-sn-glycero-3-phosphocholine (LPC) and 1-palmitoyl-2-hydroxysn-glycero-3-phospho-(1'-rac-glycerol) (sodium salt) (LPG) and, LUVs were prepared from 1-palmitoyl-2oleoyl-sn-glycero-3-phosphocholine (POPC) and 1-palmitoyl-2-oleoyl-sn-glycero-3-phospho-(1'-rac-glycerol) (sodium salt) (POPG). The peptide fEC1 was synthesized by solid-phase synthesis. Fluorescence measurements were performed using the tryptophan residue $\left(\mathrm{W}^{94}\right)$, present in the amino acid sequence of $\mathrm{fEC1}$, as an intrinsec fluorescent probe. The excitation wavelength $\left(\lambda_{\text {exc }}\right)$ was $195 \mathrm{~nm}$. The fluorescence spectra of fEC1 $(10 \mu \mathrm{M})$ were obtained at increasing concentrations of lysophospholipids or phospholipids. The fluorescence intensity of peptide in the presence of zwitterionic (LPC) and anionic (LPC: LPG, mol:mol) micelles and in the presence of anionic LUV (POPC:POPG, mol:mol) increased. Besides, upon addition of these model systems, a blue-shift of the maximum emission peak of the peptide was observed. The spectral changes observed are due to the sensitivity of tryptophan to the polarity of the medium. From the binding isotherms, binding constants $\left(\mathrm{K}_{\mathrm{b}}\right)$ were determined. According to these values, the binding of the peptide with the anionic systems was higher than with the zwitterionic ones, this is due to the contribution of electrostatic forces. For fluorescence quenching studies, acrylamide was used as a collisional quencher, thus, SternVolmer constants were determined. According to these data, the fluorophore is more exposed to acrylamide when fEC1 is in solution than in the presence of the biomimetic membrane. Moreover, the values of fluorescence anisotropy ( $r$ ) which are related to the rotational diffusion of a fluorophore were calculated. According to these data, the peptide showed higher rotational diffusion in aqueous medium than in presence of model systems. The results obtained by steady-state fluorescence show the binding of the peptide fragment fEC1 with lysophospholipid micelles, POPC: POPG LUV and, in lesser extent, with POPC LUV.

\section{Keywords: Human $A T_{1}$ receptor, circular dichroism, fluorescence, model membrane}

\section{Introducción}

Los receptores de angiotensina II son proteínas integrales de membrana, miembros de la superfamilia de receptores acoplados a Proteínas G (GPCR) [1].

Los GPCR se caracterizan por presentar una región $\mathrm{N}$-terminal, 7 hélices de transmembrana conectadas por tres bucles extracelulares y tres bucles intracelulares, y una región C-terminal intracelular. Los bucles extracelulares tienen un papel importante en la activación del receptor [2, 3].

Los receptores de angiotensina II pueden ser divididos en dos clases farmacológicas: tipo 1 ( $\mathrm{AT}_{1}$ ) y tipo $2\left(\mathrm{AT}_{2}\right)$. Esta clasificación está basada en la capacidad de interacción de antagonistas con el receptor el cual a su vez es capaz de bloquearlos [4, 5].

El receptor $A T_{1}$ humano está localizado en el cromosoma 3 [6] y presenta 359 aminoácidos [7]. Diferentes residuos de aminoácidos, tanto de la hormona angiotensina II como del receptor, que participan en la interacción angiotensina II-receptor han sido identificados, sin embargo, estos estudios han sido realizados principalmente con el receptor $A T_{1}$ de rata $\left(A T_{1 A}\right)$, ampliamente considerado como el homólogo funcional más próximo del receptor $A T_{1}$ humano [8]. Un estudio de mutagénesis sitio-dirigida, fotosondas moleculares y de modelamiento por homología [9], identificó residuos discretos de la superficie extracelular del receptor $\mathrm{AT}_{1}$ humano que participan en la formación del sitio de interacción angiotensina II-receptor.

Un enfoque para el estudio de la relación estructuraactividad de proteínas de membrana, como los GPCR, es estudiar fragmentos peptídicos sintéticos de la proteína. Los fragmentos peptídicos son capaces de adquirir las conformaciones predichas para esos dominios en la proteína entera [10]. Debido a la diversidad y complejidad de la membrana biológica y, siendo que los GPCR están inmersos en ella, los estudios conformacionales de fragmentos del receptor requieren el uso de sistemas que mimeticen la membrana biológica. Entre estos sistemas se puede mencionar: monocapas de Langmuir, bicapas lipídicas, liposomas, vesículas unilamelares gigantes (GUV), vesículas gigantes derivadas de membrana 
biológica, entre otros [11]. En este sentido, el presente estudio tiene como objetivo investigar la interacción de un fragmento peptídico del primer bucle extracelular del receptor $\mathrm{AT}_{1}$ humano con sistemas miméticos de membrana biológica.

\section{Materiales y métodos}

\subsection{Materiales}

Péptido: Ac-YRWPFGNYL-CONH 2 (fEC1), sintetizado en el Departamento de Biofísica de la Universidade Federal de São Paulo empleando el método de síntesis en fase sólida [12, 13].

Fosfolípidos (Avanti Polar Lipids, Inc.): 1-palmitoyl-2oleoyl-sn-glycero-3-phosphocholine (POPC) y 1palmitoyl-2-oleoyl-sn-glycero-3-phospho-(1'-racglycerol) (sodium salt) (POPG).

Lisofosfolípidos (Avanti Polar Lipids, Inc.): 1palmitoyl-2-hydroxy-sn-glycero-3-phosphocholine (LPC) y 1-palmitoyl-2-hydroxy-sn-glycero-3-phospho(1'-rac-glycerol) (sodium salt) (LPG).

\subsection{Métodos}

Determinación de la concentración de fEC1: fue determinada de acuerdo a Pace et al. (1995) [14] en un espectrofotómetro UV-Vis Hitachi modelo U-2010 usando cubetas de quarzo de camino óptico $0.5 \mathrm{~cm}$.

Preparación de vesículas y micelas: La concentración de las soluciones stock de los fosfolípidos fue determinada mediante el método de Rouser et al. (1970) [15]. Las vesículas unilamelares grandes (large unilamellar vesicles, LUV) fueron preparadas en un aparato extrusor (Liposofast, de AVESTIN, Ottawa - Canadá) utilizando membranas de policarbonato con diámetro de poro de $100 \mathrm{~nm}$.

Para la preparación de soluciones micelares de LPC y LPG (100 mM), una masa determinada de lisofosfolípido fue disuelta en un volumen determinado de tampón PBC 10 mM.

Determinación de la carga teórica de fEC1: fue calculado de acuerdo a Skoog y Wichman (1986) [16].

Determinación de las constantes de asociación $\left(\mathrm{K}_{\mathrm{a}}\right)$ : Fueron obtenidas a partir de los ajustes de las isotermas de interacción a una hipérbola rectangular. Para el cálculo de $K_{a}$ se asume una estequiometría de una molécula de péptido para una molécula de lisofosfolípido o fosfolípido [17].
Cálculo de la variación de energía libre standard de transferencia $\left(\Delta \mathrm{G}^{\circ} \mathrm{x}\right)$ para la interacción del péptido con los sistemas miméticos de membrana biológica: fue realizado de acuerdo a White y Wimley (1999) [18].

Determinación de las constantes de Stern-Volmer (Ksv): Fueron calculados a partir de la ecuación: $F_{0} / F=1+K_{s v}$. [Q], donde: $F_{0} / F$ es la fluorescencia relativa y [Q] es la concentración de la molécula supresora de la fluorescencia, acrilamida $\left(\mathrm{CH}_{2}=\mathrm{CH}\right.$ $\mathrm{CONH}_{2}$ ) [19].

Cálculo de anisotropia de fluorescencia (r): Para este estudio la luz de excitación y de emisión son polarizadas vertical y horizontalmente. $r$ fue calculado mediante la siguiente ecuación:

$$
r=\frac{I_{\mathrm{v}}-\mathrm{GI}_{\mathrm{VH}}}{\mathrm{I}_{\mathrm{V}}+2 \mathrm{G} \mathrm{I}_{\mathrm{VH}}}
$$

Donde $I_{V V}$ y $I_{V H}$ son las intensidades de radiación emitida por el fluoróforo en orientaciones paralela y perpendicular, respectivamente, al plano de la luz de excitación que es vertical en relación a las coordenadas del laboratorio. $G$ es un factor de corrección [19].

Obtención de los espectros de fluorescencia: fueron adquiridos en un espectrofluorímetro Hitachi F-4500 utilizando cubetas de quarzo de $1.0 \mathrm{~cm}$ de camino óptico y hendiduras de emisión y de excitación de 5 $\mathrm{nm}$. La longitud de onda de excitación $\left(\lambda_{\text {exc }}\right)$ fue 295 $\mathrm{nm}$. La concentración de fEC1 fue $10 \mu \mathrm{M}$. Las intensidades de fluorescencia fueron corregidas por efecto de dilución de las muestras.

Los experimentos fueron realizados en temperatura ambiente $\left(21 \pm 1^{\circ} \mathrm{C}\right)$.

\section{Resultados y discusión}

El fragmento peptídico fEC1, cuya secuencia corresponde al primer bucle extra-celular del receptor $A T_{1}$ humano, posee nueve residuos de aminoácidos de los cuales tres presentan grupos ionizables: $Y^{92}, R^{93}$ y $Y^{99}$. En el receptor $A T_{1 A}$ el residuo $\mathrm{Y}^{92}$ es uno de los residuos importantes para la interacción con el agonista [20].

El perfil de la variación de la carga teórica del péptido en función del pH es mostrado en la figura 1. En la determinación de la carga teórica, la ionización de $\mathrm{N}$ - y C-terminales no fue considerada debido a que el péptido está acetilado y amidado en el $\mathrm{N}$ - y en 
el C-terminal respectivamente. El punto isoeléctrico (pl) de fEC1 determinado corresponde al valor de 10.06 .

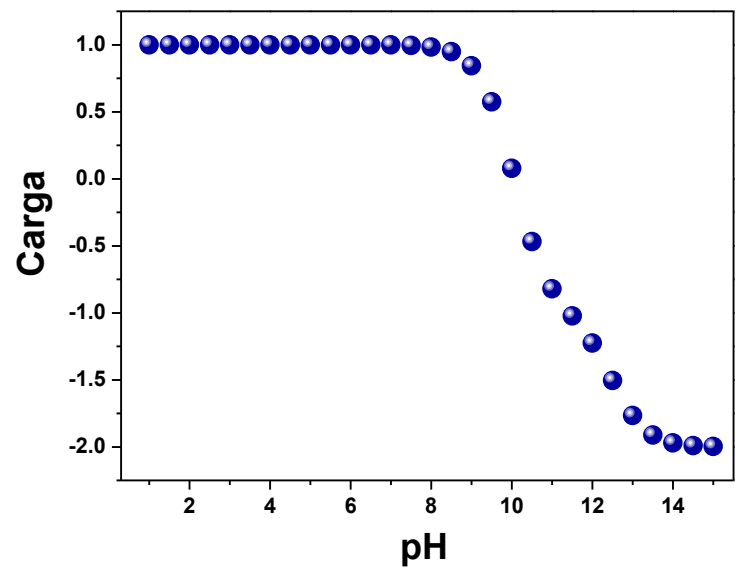

Figura 1: Variación de la carga teórica de fEC1 en función del $\mathrm{pH}$.

El péptido fEC1 presenta $44.4 \%$ de residuos aromáticos con propiedades fluorescentes: dos tirosinas, una fenilalanina y un triptófano. Este último aminoácido presenta mayor rendimiento cuántico que los otros residuos aromáticos [19], siendo así, el residuo $\mathrm{W}^{94}$ fue utilizado como fluoróforo intrínseco para los estudios de fluorescencia. Una característica importante del triptófano es que presenta carácter anfipático; por un lado, el grupo $\mathrm{NH}$ del indol es capaz de formar puentes de hidrógeno, y por otro, el triptófano presenta mayor hidrofobicidad interfacial con respecto a otros aminoácidos naturales [19].

Los valores de longitud de onda de excitación del triptófano $\left(\lambda_{\text {exc }} 280 \mathrm{~nm}\right)$ y de tirosina $\left(\lambda_{\text {exc }} 275 \mathrm{~nm}\right)$ son muy cercanos y, para evitar la excitación de la tirosina, el valor empleado de $\lambda_{\text {exc }}$ para el triptófano fue de $295 \mathrm{~nm}$. La figura 2 ilustra los espectros de fluorescencia de fEC1 en diferentes $\mathrm{pH}$ en solución acuosa. Se observa una disminución de la intensidad de fluorescencia desde pH 3.0 hasta $\mathrm{pH}$ 10.0 sin cambio notable en la longitud de onda de emisión máxima de fluorescencia $\left(\lambda_{\max }\right)$ que se mantiene entre 345 y $347 \mathrm{~nm}$. En pH 11.0 el valor de $\lambda_{\max }$ se desplaza para $352 \mathrm{~nm}$. La disminución de la intensidad de fluorescencia con el aumento del $\mathrm{pH}$ se debe a la ionización de las dos tirosinas presentes en la secuencia de aminoácidos de fEC1 con consecuente formación de tirosinato.

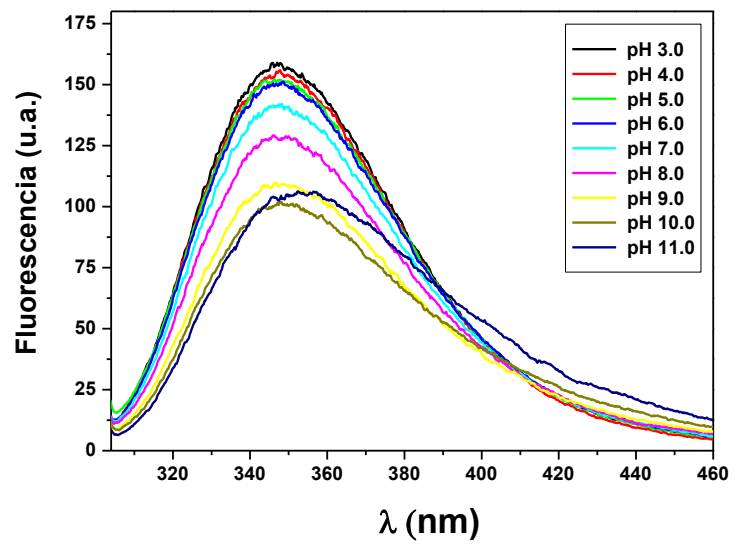

Figura 2: Espectros de fluorescencia de fEC1 en diferentes $\mathrm{pH}$.

El triptófano es sensible a la polaridad del medio; esta propiedad es de gran utilidad para estudios de interacción con sistemas miméticos de membrana biológica [19]. De esta manera, se investigó la interacción de fEC1 con micelas y LUV. Para este fin, en la muestra de péptido de concentración fija $(10 \mu \mathrm{M})$ fueron adicionadas concentraciones crecientes de sistema mimético de membrana hasta saturación y, registrados los espectros de emisión de fluorescencia.

En la figura 3 se presentan los espectros de fluorescencia de fEC1, en $\mathrm{pH} 7.0(\mathrm{pH}$ próximo al $\mathrm{pH}$ fisiológico), en la presencia de LPC en concentraciones mayores a la concentración micelar crítica, cuyo valor para LPC, es 0.005 mM [21].

En solución acuosa, se observa que la intensidad de fluorescencia máxima $\left(F_{\max }\right)$ de $f E C 1$ se encuentra en alrededor de $347 \mathrm{~nm}$. Sin embargo, en la presencia de las micelas, la intensidad de fluorescencia aumentó en poco más del doble, además, hubo desplazamiento del pico de emisión máxima de fluorescencia para menores longitudes de onda (entre 335 y $336 \mathrm{~nm}$ ) (desplazamiento para el azul). Esto se explica debido a que el anillo de indol del triptófano es altamente sensible al medio donde se encuentra. Los cambios observados, cuando el fluoróforo pasa de un ambiente polar a otro menos polar, muestra la interacción del péptido con el sistema mimético de membrana en estudio. 


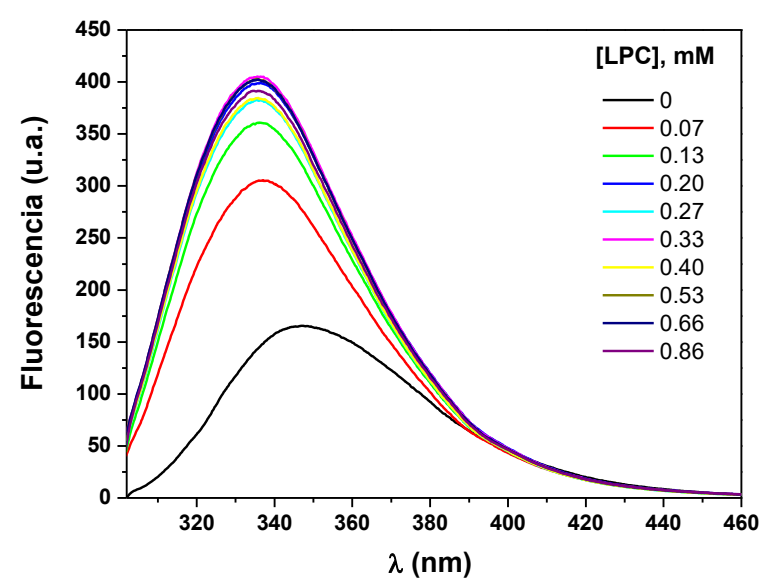

Figura 3: Espectros de fluorescencia de fEC1 en la presencia de micelas de LPC. pH 7.0.

En la figura 4 se ilustran los perfiles de variación de $F_{\max } y$ de $\lambda_{\max }$ de fEC1 en función de la concentración de LPC.

En la presencia de micelas de LPC: LPG, la intensidad de fluorescencia de fEC1 aproximadamente se duplica a partir de bajas concentraciones de LPC: LPG permaneciendo constante a partir de $\sim 0.2 \mathrm{mM}$ como puede ser observado en la figura 5. En la saturación con micelas, el valor de $\lambda_{\max }$ está entre 334 y $335 \mathrm{~nm}$. Estos datos indican la interacción de fEC1 con las micelas aniónicas, la que puede ser favorecida por fuerzas electrostáticas teniendo en cuenta que el péptido está con carga positiva ${ }^{+1}$ en $\mathrm{pH}$ neutro.

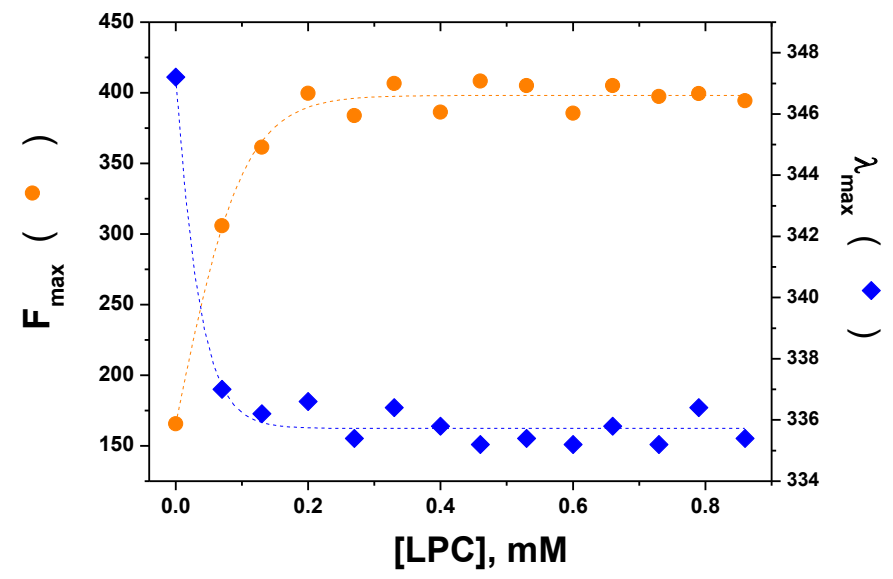

Figura 4: Fmax y $\lambda_{\max }$ de fEC1 en función de la concentración de LPC. pH 7.0.

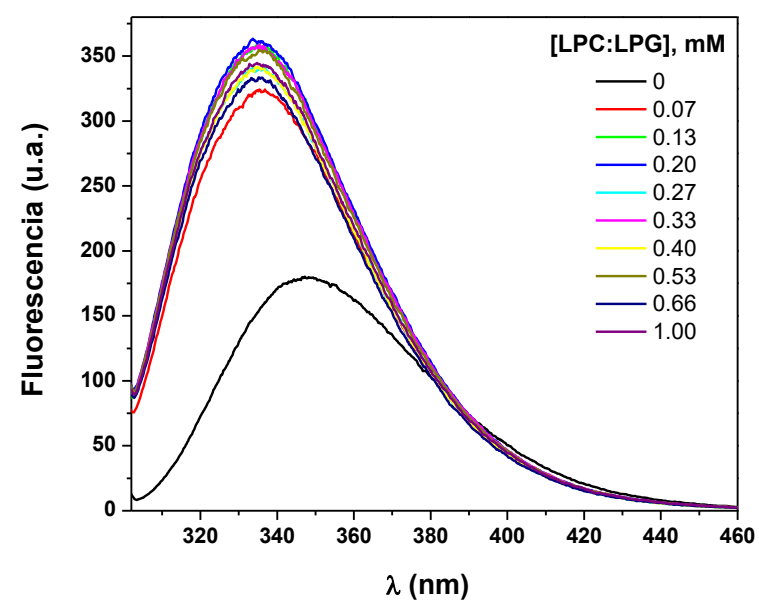

Figura 5: Espectros de fluorescencia de fEC1 en la presencia de micelas de LPC: LPG (1:1, mol:mol). pH 7.0.

Contrario a lo observado en la presencia de micelas, en la presencia de LUV de POPC las intensidades de fluorescencia disminuyeron ligeramente con el aumento de la concentración de fosfolípido como se muestra en la figura 6 . Sin embargo, los valores de $\lambda_{\max }$ se desplazaron ligeramente para el azul (a 341-343 nm) lo cual sugiere que hay interacción del fragmento peptídico con las vesículas zwitteriónicas.

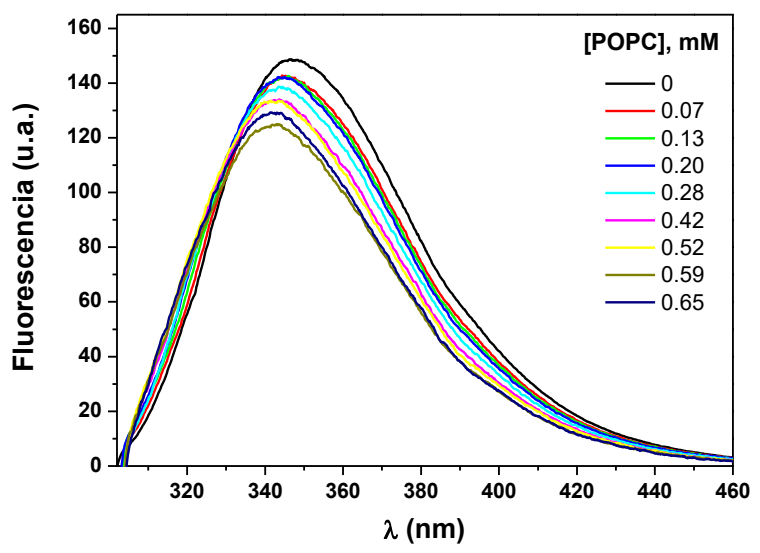

Figura 6: Espectros de fluorescencia de fEC1 en la presencia de LUV de POPC. pH 7.0.

En la titulación de fEC1 con las LUV de POPC: POPG (figura 7), la intensidad de fluorescencia aumenta en más del doble, alcanzando su valor máximo en $\sim 0.5 \mathrm{mM}$. También, se puede observar que los valores de $\lambda_{\max }$ se desplazaron para $\sim 334$ 
nm. Estos resultados muestran la interacción de fEC1 con las vesículas aniónicas.

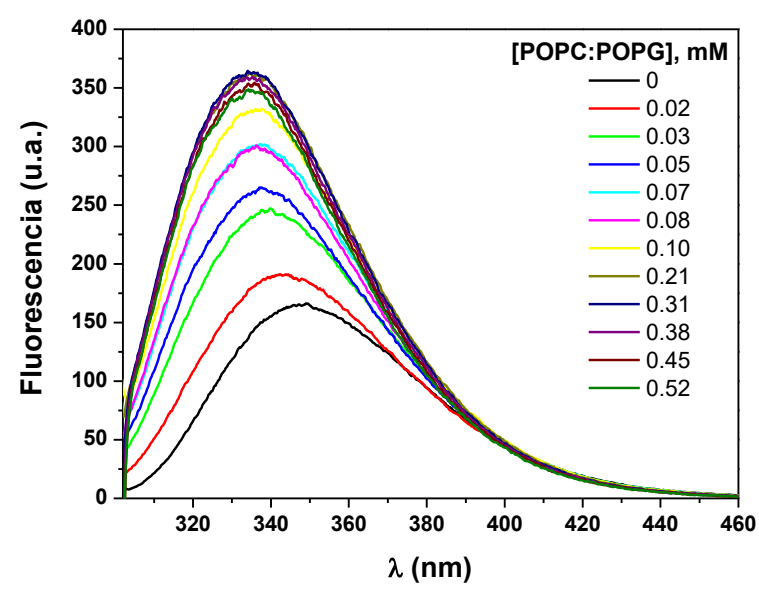

Figura 7: Espectros de fluorescencia de fEC1 en la presencia de LUV de POPC: POPG (1:1, mol:mol). pH 7.0.

El desplazamiento de $\lambda_{\max }$ para el azul es menor cuando el péptido está en la presencia de LUV de POPC (figura 6) que en la presencia de los otros sistemas estudiados indicando que fEC1 estaría más en contacto con moléculas de agua en la interface membrana-agua.

A partir de los datos de fluorescencia fueron obtenidos los valores de $\mathrm{K}_{\mathrm{a}}$ y $\Delta \mathrm{G}^{\circ}{ }_{\mathrm{x}}$ para la interacción péptido-sistema modelo, excepto para la interacción con LUV de POPC (Tabla 1). En este último caso, los datos de fluorescencia no se ajustaron a una hipérbola rectangular. De acuerdo a los valores de $K_{a}$, fEC1 interactúa más con las micelas aniónicas que con las zwitteriónicas. Entre los sistemas aniónicos, el péptido presenta mayor interacción con las micelas que con las vesículas. El mayor valor, en módulo, de $\Delta \mathrm{G}^{\circ}{ }_{\mathrm{x}}$ correspondió a la interacción del péptido con las micelas de LPC:LPG.

Tabla 1: Valores de $K_{a}$ y $\Delta G_{x}^{\circ}$ de la interacción de fEC1 con sistemas miméticos de membrana biológica. $\mathrm{pH}$ 7.0.

\begin{tabular}{lcc}
\hline & $\begin{array}{c}\mathrm{K}_{\mathrm{a}} \times 10^{3} \\
\left(\mathrm{M}^{-1}\right)\end{array}$ & $\begin{array}{c}\Delta \mathrm{G}^{\circ}{ }_{\mathrm{x}} \\
\left(\mathrm{kcal}^{-1} \mathrm{~mol}^{-1}\right)\end{array}$ \\
\hline \hline LPC & 20.0 & -8.17 \\
\hline LPC:LPG & 40.0 & -8.57 \\
\hline POPC:POPG & 20.8 & -8.19 \\
\hline
\end{tabular}

También, se realizaron medidas de fluorescencia de fEC1 en la presencia de acrilamida, la cual causa supresión de la fluorescencia del triptófano. Esta supresión es de tipo colisional o dinámico, el cual, consiste en que, la molécula supresora colide con el fluoróforo durante el tiempo de vida del estado excitado. Después del contacto, el fluoróforo retorna al estado fundamental sin emisión de fotón [19]. En la figura 8 se muestran los espectros de fluorescencia de fEC1 en solución en concentraciones crecientes de acrilamida. Se observa disminución de la intensidad de fluorescencia de fEC1 con el aumento de la concentración de acrilamida. La supresión del grupo indol por acrilamida probablemente es debida a la transferencia de electrones del indol a la acrilamida, lo cual no ocurre en el estado fundamental [19].

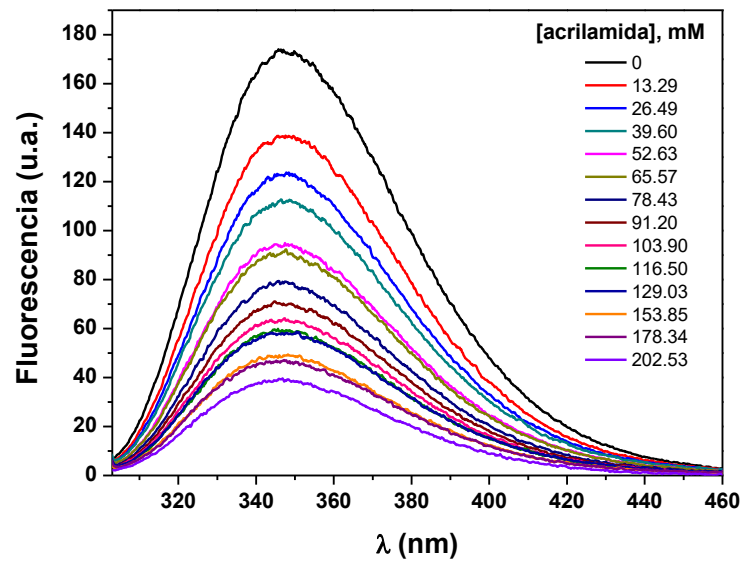

Figura 8: Espectros de fluorescencia de fEC1 en solución en presencia de acrilamida. pH 7.0.

Los estudios también fueron realizados en la presencia de sistema modelo (en la concentración de saturación). Debido a su naturaleza hidrofílica, la acrilamida se localiza en la interface hidrofóbicahidrofílica. La figura 9 muestra los valores de fluorescencia relativa $\left(F_{0} / F\right)$ en la ausencia y en la presencia de micelas de LPC: LPG y de LUV de POPC:POPG en concentraciones crecientes de acrilamida. Los valores de $F_{0} / F$ se ajustaron a una recta y se puede observar que la pendiente de la recta, correspondiente al péptido en solución, es mayor que las otras correspondientes al péptido en la presencia de los sistemas modelo. Esta mayor pendiente muestra mayor accesibilidad a la acrilamida cuando el péptido está en solución que en la presencia de dichos sistemas. 


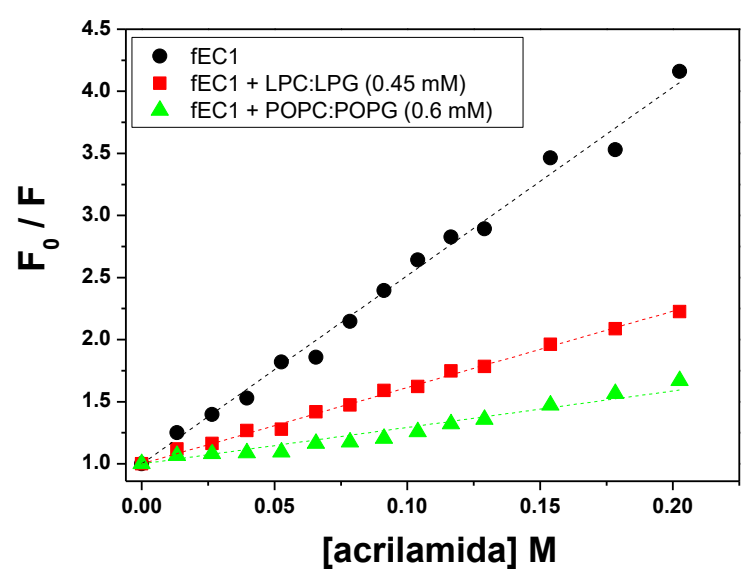

Figura 9: Fluorescencia relativa de fEC1 en solución y en presencia de sistemas miméticos de membrana biológica en función de la concentración de acrilamida. $\mathrm{pH}$ 7.0.

Asimismo, la cuantificación del grado de supresión de fluorescencia fue realizada determinando los valores de $\mathrm{K}_{\mathrm{sv}}$ en $\mathrm{pH}$ diferentes para determinar el efecto del $\mathrm{pH}$ sobre la interacción, considerando que, el péptido presenta cargas diferentes en diferentes $\mathrm{pH}$ debido a la presencia de residuos de aminoácidos que presentan grupos ionizables. Cabe mencionar que, el pK de un aminoácido libre podría verse alterado cuando el aminoácido forma parte de una secuencia peptídica debido a efectos del campo eléctrico de residuos de aminoácidos próximos y, a la polaridad del medio. Asimismo, los cambios de pK también pueden ocurrir debido a la interacción péptido-membrana [22].

Los valores de $\mathrm{K}_{s v}$ son mostrados en la tabla 2 e indican menor efecto de supresión de la fluorescencia cuando el péptido está en la presencia de sistemas de membranas modelo, indicando, por tanto, interacción del péptido con estos sistemas.

Tabla 2: Valores de Ksv para la supresión de fluorescencia de fECL1 por acrilamida en solución y en la presencia de sistemas miméticos de membrana biológica.

\begin{tabular}{lccc}
\hline & \multicolumn{3}{c}{$\mathbf{K}_{\mathbf{s v}}\left(\mathbf{M}^{-1}\right)$} \\
\cline { 2 - 4 } & $\mathbf{p H ~ 4 . 0}$ & $\mathbf{p H ~ 7 . 0}$ & $\mathbf{p H ~ 1 0 . 0}$ \\
\hline Tampón PBC & 15.66 & 15.17 & 12.54 \\
\hline LPC:LPG (0.45 mM) & 5.83 & 6.15 & 6.03 \\
\hline POPC:POPG (0.6 mM) & 3.23 & 2.93 & 4.08 \\
\hline
\end{tabular}

Por otro lado, en medio acuoso, los valores de $\mathrm{K}_{\mathrm{sv}}$ dependieron del $\mathrm{pH}$ del medio. En los $\mathrm{pH} 4.0$ y 7.0 fEC1 presenta carga ${ }^{+} 1$, con similares valores de $\mathrm{K}_{\mathrm{sv}}$, mientras que, en $\mathrm{pH} 10.0$ la carga es próximo de cero conforme a la figura 1.

Otro parámetro importante que puede brindar información acerca de la interacción péptido-sistema biomimético es la anisotropía de fluorescencia $(r)$ el cual está relacionado al movimiento de difusión rotacional de un fluoróforo. En solución fluída, la mayoría de fluoróforos rotan extensivamente en 50 a 100 ps, de esta manera, las moléculas pueden rotar varias veces durante el tiempo de vida de estado excitado de 1-10 ns. En solución, los fluoróforos típicamente muestran valores de $r$ próximos de cero [19]. El valor calculado de $r$ para fEC1 en solución fue 0.0292 el cual aumentó a 0.0576 en la presencia de micelas de LPC: LPG y, a 0.0372 en la presencia de LUV de POPC: POPG en pH 4.0. Estos datos indican una disminución del movimiento de difusión rotacional del péptido en la presencia de los sistemas biomiméticos en estudio, lo cual, puede explicarse debido a la interacción con éstos.

\section{Conclusiones}

Los diferentes parámetros espectrales obtenidos a partir de las medidas de fluorescencia tales como fluorescencia máxima, longitud de onda de emisión máxima, $\mathrm{K}_{\mathrm{a}}, \mathrm{K}_{\mathrm{sv}}$ y $\mathrm{r}$ son herramientas importantes en la determinación de la interacción péptido-sistema modelo. Los resultados obtenidos mostraron la interacción del fragmento peptídico fEC1 con las micelas de lisofosfolípido, zwiteriónica y aniónica, así como, con las LUV aniónicas de POPC: POPG y, en menor extensión, con las LUV de POPC.

\section{Agradecimentos}

Agradecemos al Conselho Nacional de Desenvolvimento Científico e Tecnológico (CNPq) por el financiamiento del presente estudio.

\section{Referencias}

[1] M. de Gasparo, K.J. Catt, T. Inagami, J.W. Wright, TH. Unger. Pharmacol. Rev. 52 (2000) 415-472.

[2] M.C. Peeters, G.J.P. van Westen, Q. Li, A.P. IJzerman. Trends Pharmacol. Sci. 32 (2011) 35-42.

[3] M. Wheatley, D. Wootten, M.T. Conner, J. Simms, R. Kendrick, R.T. Logan, D.R. Poyner, J. Barwell. British J. Pharmacol. 165 (2012) 1688-1703. 
[4] P.B. Timmermans, A.T. Chiu, W.F. Herblin, P.C. Wong, R.D. Smith. Am. J. Hypertens. 5 (1992) 406-410.

[5] R.D. Smith, P.B. Timmermans. Curr. Opin. Nephrol. Hypertens. 3(1) (1994) 112-122.

[6] C. Szpirer, M. Rivière, J. Szpirer, G. Levan, D.F. Guo, N. Iwai, T. Inagami. J. Hypertens. 11 (1993) 919-925.

[7] H. Furuta, D.F. Guo, T. Inagami. Biochem. Biophys. Res. Commun. 183 (1992) 8-13.

[8] L. Oliveira, C.M. Costa-Neto, C.R. Nakaie, S. Schreier, S.I. Shimuta, A.C.M. Paiva. Physiol. Rev. 87 (2007) 565-592.

[9] D. Fillion, J. Cabana, G. Guillemette, R. Leduc, P. Lavigne, E. Escher. J. Biol. Chem. 288(12) (2013) 8187-8197.

[10] P.L. Yeagle, A.D. Albert. Biochim. Biophys. Acta 1768 (2007) 808-824.

[11] A. Czogalla, M. Grzybek, W. Jones, Ü. Coskun. Biochim. Biophys. Acta 1841 (2014) 1049-1059.

[12] R.B. Merrifield. J. Am. Chem. Soc. 85 (1963) 2149-2154.

[13] J.M. Stewart, J.D. Young. Solid phase peptide synthesis. Pierce Chemical Co., Rockford. 1984.
[14] C.N. Pace, F. Vajdos, L. Fee, G. Grimsley, T. Gray. Protein Sci. 4 (1995) 2411-2423.

[15] G. Rouser, S. Fkeischer, A. Yamamoto. Lipids 5 (1970) 494-496.

[16] B. Skoog, A. Wichman. Trends Anal. Chem. 5 (1986) 82-83.

[17] T.D. Pollard. A Guide to simple and informative binding assays. Mol. Biol. Cell 21 (2010) 40614067.

[18] S.H. White, W.C. Wimley. Annu. Rev. Biophys. Biomol. Struct. 28 (1999) 319-365.

[19] J.R. Lakowicz. Principles of Fluorescence Spectroscopy. 3ra. ed. Springer Science + Business Media, LCC, New York, NY. 2006.

[20] S.A. Hjorth, H.T. Schambye, W.J. Greenlee, T.W. Schwartz. J. Biol. Chem. 269 (1984) 30953-30959.

[21] H. Heerklotz, R.M. Epand. Biophys. J. 80 (2001) 271-279.

[22] R.K. Salinas, C.S. Shida, T.A. Pertinhez, A. Spisni, C.R. Nakaie, A.C.M. Paiva, S. Schreier. Biopolymers 65 (2002) 21-31.

E-mail: nelida marin@yahoo.com 